\title{
A model of osteoporosis impact in Switzerland 2000-2020
}

\author{
Matthias Schwenkglenks · Kurt Lippuner \\ Hans Jörg Häuselmann · Thomas D. Szucs
}

Received: 19 September 2003 / Accepted: 18 August 2004/Published online: 26 October 2004

(C) International Osteoporosis Foundation and National Osteoporosis Foundation 2004

\begin{abstract}
The aim of our study was to develop a modeling framework suitable to quantify the incidence, absolute number and economic impact of osteoporosisattributable hip, vertebral and distal forearm fractures, with a particular focus on change over time, and with application to the situation in Switzerland from 2000 to 2020. A Markov process model was developed and analyzed by Monte Carlo simulation. A demographic scenario provided by the Swiss Federal Statistical Office and various Swiss and international data sources were used as model inputs. Demographic and epidemiologic input parameters were reproduced correctly, confirming the internal validity of the model. The proportion of the Swiss population aged 50 years or over will rise from $33.3 \%$ in 2000 to $41.3 \%$ in 2020 . At the total population level, osteoporosis-attributable incidence will rise from 1.16 to 1.54 per 1,000 person-years in the case of hip fracture, from 3.28 to 4.18 per 1,000 person-years in the case of radiographic vertebral fracture, and from 0.59 to 0.70 per 1,000 person-years in the case of distal forearm fracture. Osteoporosis-attributable hip fracture numbers will rise from 8,375 to 11,353 , vertebral fracture numbers will rise from 23,584 to 30,883 , and distal forearm fracture numbers will rise from 4,209 to 5,186. Population-level osteoporosis-related direct medical inpatient costs per year will rise from 713.4 million Swiss francs
\end{abstract}

M. Schwenkglenks $(\square)$

ECPM Executive Office, University Hospital, 4031, Basle, Switzerland

E-mail: m.schwenkglenks@unibas.ch

Tel.: + 41-61-2614583

Fax: +41-61-2614584

M. Schwenkglenks · T. D. Szucs

European Center of Pharmaceutical Medicine,

University of Basel, Basle, Switzerland

K. Lippuner

Osteoporosis Unit, Inselspital, Berne, Switzerland

H. J. Häuselmann

Centre of Rheumatology and Bone Diseases,

Klinik Im Park, Zurich, Switzerland
(CHF) to CHF946.2 million. These figures correspond to $1.6 \%$ and $2.2 \%$ of Swiss health care expenditures in 2000. The modeling framework described can be applied to a wide variety of settings. It can be used to assess the impact of new prevention, diagnostic and treatment strategies. In Switzerland incidences of osteoporotic hip, vertebral and distal forearm fracture will rise by $33 \%$, $27 \%$, and $19 \%$, respectively, between 2000 and 2020 , if current prevention and treatment patterns are maintained. Corresponding absolute fracture numbers will rise by $36 \%, 31 \%$, and $23 \%$. Related direct medical inpatient costs are predicted to increase by $33 \%$; however, this estimate is subject to uncertainty due to limited availability of input data.

Keywords Economics - Epidemiology - Europe · Modeling studies $\cdot$ Osteoporosis $\cdot$ Switzerland

\section{Introduction}

Osteoporosis is an important health problem in elderly women and, to a lesser extent, in elderly men [1]. Osteoporotic fragility fractures occur at multiple sites of the skeletal system [2], but the main focus of research is on fractures of the hip, vertebrae and distal forearm [1]. These fracture types occur frequently and show a steep rise in incidence with age, more pronounced in women than in men $[1,3]$. Most serious consequences are observed in hip and vertebral fracture patients. The impact of hip fracture is dramatic in terms of morbidity, mortality, loss of functional independence, and cost $[1,4]$.

Worldwide projections have predicted a doubling of hip fracture cases from 1990 to 2025, with the ageing of the populations being one of the most important causes $[5,6]$. The expected rise will be particularly pronounced in Asia, but Western societies will be affected, too $[5,7]$.

Despite an awareness of these general trends, detailed simulations of the future impact of osteoporosis are rare. Several Markov-based modeling studies have assessed lifetime fracture risk and long-term fracture 
consequences $[8,9,10,11]$, but only one, focusing on the situation in Florida, has examined the expected health burden of osteoporosis in the first quarter of the 21st century [12].

In Switzerland, countrywide data on the occurrence and impact of osteoporotic fractures are sparse, with the last comprehensive assessment describing the situation in 1992 [13]. Forecasts of future fracture incidences and impact were based on these data and did not apply upto-date modeling techniques $[14,15]$. A Swiss Markov model, addressing the socioeconomic impact of hip fracture, has been published as a short report only [16]. A clear lack of planning data has been recognized by the health authorities.

Given this situation, we aimed at developing a Markov-based modeling framework using Monte Carlo simulation, suitable to quantify the incidence, absolute number and economic impact of osteoporotic hip, vertebral and distal forearm fractures, currently and in the future. Intended features were applicability to a wide variety of countries and situations, and the ability to assess the impact of future changes in disease incidence, osteoporosis-related medical practice, and cost. The first application was to the Swiss population in 2000, 2010 and 2020. The methodological objective of this application was to test the model in a well-defined and stable Western population with a high share of elderly people. At the same time the existing knowledge gap with respect to the current situation and the developments to be expected in Switzerland was to be filled.

\section{Materials and methods}

\section{Model characteristics}

Using DATA Professional (Tree Age, Williamstown, Mass., USA), we developed a four-stage Markov process model comprising the following mutually exclusive health states: alive without fracture; alive with at least one distal forearm or vertebral fracture, but no hip fracture; alive with at least one hip fracture; dead. Other fracture sites were not taken into account. We used Monte Carlo simulation to run a large number of individuals through the model separately, allowing for a subject-by-subject random assignment of characteristics. We used tracker variables to record individual event histories, taking into account non-osteoporotic and osteoporotic fractures, acute hospital care, inpatient rehabilitation episodes, nursing home admissions, and cost. Thus, the "memory-less" feature of Markov cohort models was overcome [17].

We modeled all event entries using a cycle length of 1 month, in order to reduce any distortions related to the time distribution of events occurring. An individual could sustain one fracture per cycle. Rates were converted into cumulative probabilities to allow for correct Markov state transitions between cycles [18]. Where appropriate, a half-cycle correction was implemented.
For the application to Switzerland, two different kinds of simulation were used. First, a cohort representing the Swiss population of a certain year aged 50 years or older was observed for 1 year. Based on a random assignment of gender and age, 500,000 simulated persons were run through the model. Total and osteoporosis-related hip, vertebral, and distal forearm fractures were counted. We observed fracture-related resource use and costs for another 6 months, without allowing for additional fracture entries, in order to achieve a mean follow-up time of 1 year after fracture entry. Second, a cohort representing all Swiss persons aged 50 years in a certain year was observed for the remainder of their lives. Based on a random assignment of gender, 12,500 simulated persons were run through the model. Costs were calculated undiscounted and discounted by $3 \%$ per year. Inflation or changes in inpatient care cost due to changing medical practice were not modeled. Owing to the extended observation period per subject, the relative importance of long-term nursing home costs was adequately taken into account. On this basis, estimates of mean yearly inpatient costs due to recent, as well as earlier, fractures could be calculated.

\section{Model inputs}

Published or publicly available Swiss data sources were used wherever possible. Otherwise, European data and, if necessary, data from the USA and Australia were used. Plausibility of all model inputs was assessed by comparison with published literature.

Demographic data: The Swiss Federal Statistical Office (SFSO) has issued a series of demographic scenarios projecting the development of the Swiss population between 2000 and 2060 [19]. Age and gender distributions used in the main analysis are those described by the SFSO main scenario, which extrapolates current demographic trends and thus avoids extreme assumptions. In this scenario, the proportion of the population aged 50 years or over will rise from $33.3 \%$ in 2000 to $41.3 \%$ in 2020 . The share of those aged 65 or over will rise from $15.4 \%$ to $20.0 \%$. Figure 1 compares the age distributions expected for 2000 and 2020.

Fracture incidences: Swiss hospitals are obliged to report patient-level inpatient data to the SFSO. Genderand age-specific hip fracture incidences were estimated from the ICD-10 S72.0-S72.2 cases reported to the SFSO in 2000, with the assumption of a hip fracture hospitalization rate of $100 \%$. Reporting was incomplete, and the SFSO calculated a relation of reported to expected cases of 0.811 . This figure was used with the assumption of a random distribution of non-reporting. Swiss-based gender- and age-specific data on vertebral and distal forearm fracture incidence were not available. Cases reported to the SFSO could not be used here, as valid Swiss data on hospitalization probabilities do not exist. Published data show that hip fracture rates are 
Fig. 1 Age distribution of the Swiss population, 2000 and 2020 compared, according to the Swiss Federal Statistical Office's main demographic scenario

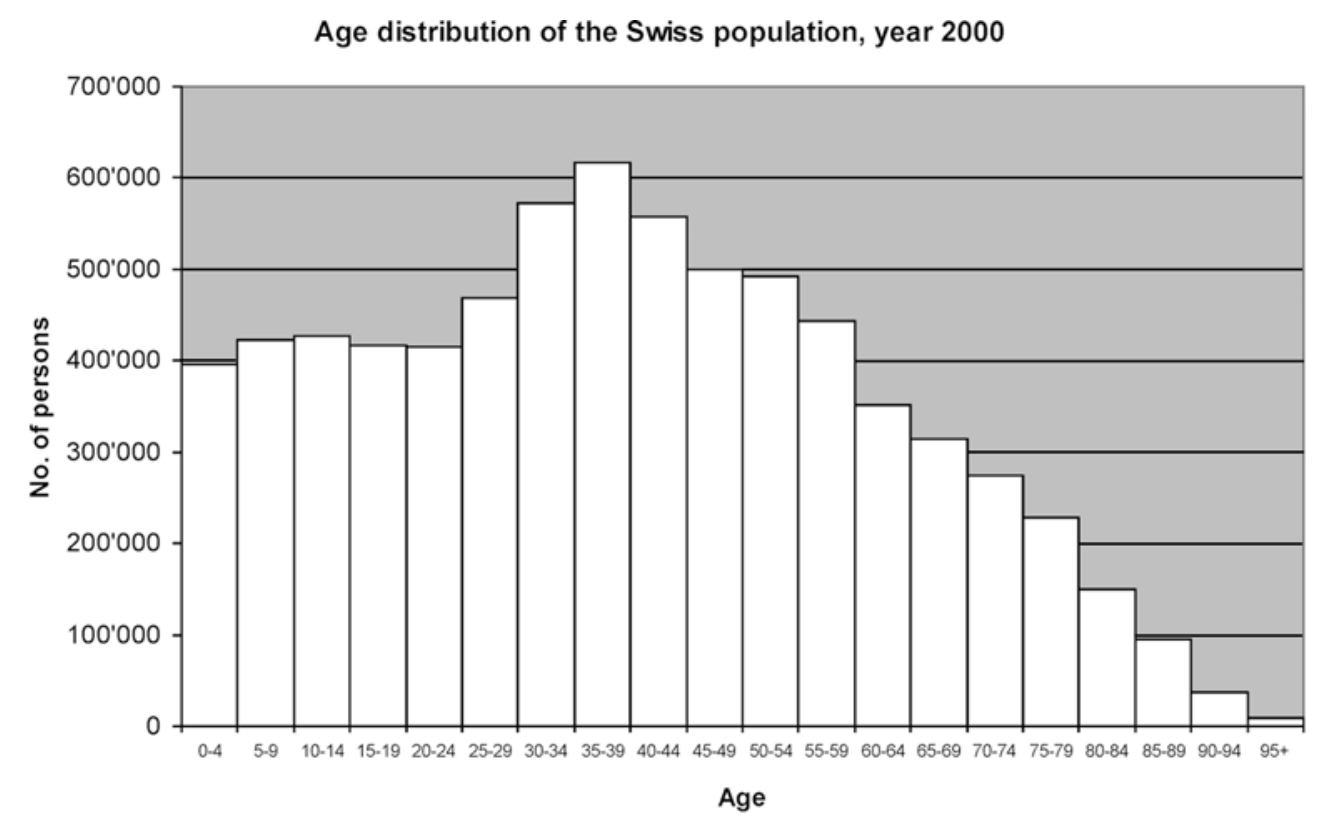

Age distribution of the Swiss population, year 2020

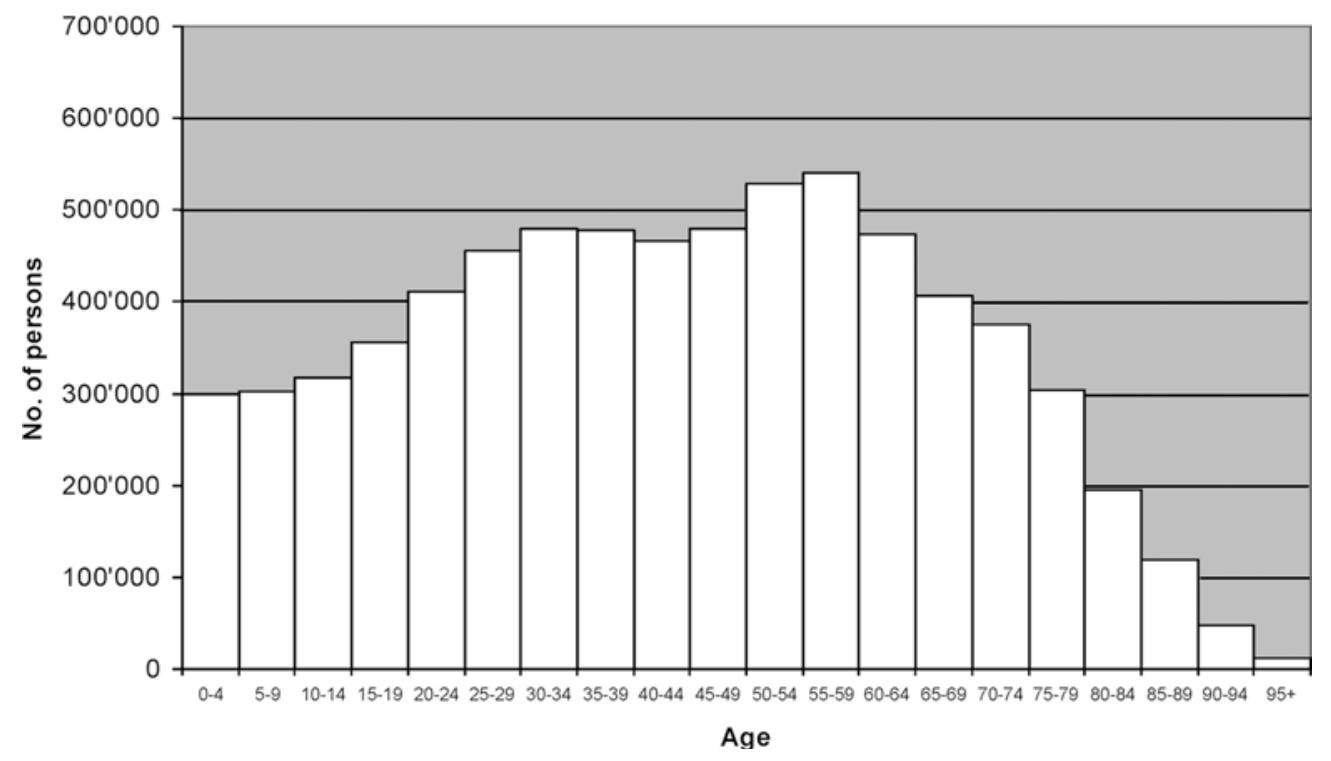

similar in Switzerland and in Western Europe [6, 20]. It was assumed that the same relationship exists for other types of osteoporotic fractures, and morphometric vertebral fracture incidences for Western Europe reported by the EPOS group were used [21]. Missing data points after age 79 years were estimated by linear extrapolation $[21,22,23,24]$. In the case of distal forearm fracture, the incidences reported by Kanis et al. for Malmö, Sweden, provided sufficient detail [23]. These were multiplied by a correction factor of 0.55 , derived from the EVOS data, as distal forearm fracture incidences are higher in Northern Europe than in Western Europe [1, 25]. Incidences above age 89 years were assumed to be identical to those in the age group $85-89$ years $[22,23,24]$. The incidence rates used are summarized in Table 1.
Osteoporosis-attributable fractures: The share of osteoporosis-attributable fractures, i.e., of fractures that would not have occurred if no osteoporotic changes had been present in the skeletal system, by fracture type, gender and age was modeled by way of a stochastic process that used the attribution probabilities described by Melton et al. for the white population in the USA [26]. Calculation of osteoporosis-attributable fracture incidences and numbers at the total population level assumed no osteoporosis-related fractures under the age of 50 years.

Mortality: All-cause mortality by year, gender and age was taken from the SFSO main demographic scenario [19]. Short- and long-term excess mortality after hip fracture was modeled from data collected by Trombetti 
Table 1 Gender- and age-specific fracture incidence rates, per 1,000 person-years, as used in the main analysis

\begin{tabular}{|c|c|c|c|c|c|c|}
\hline \multirow[t]{2}{*}{ Age (years) } & \multicolumn{2}{|c|}{ Hip fracture } & \multicolumn{2}{|c|}{$\begin{array}{l}\text { Vertebral } \\
\text { fracture }^{\mathrm{a}}\end{array}$} & \multicolumn{2}{|c|}{$\begin{array}{l}\text { Distal forearm } \\
\text { fracture }\end{array}$} \\
\hline & Female & Male & Female & Male & Female & Male \\
\hline $50-54$ & 0.31 & 0.49 & 3.6 & 0.9 & 2.3 & 0.6 \\
\hline $55-59$ & 0.68 & 0.79 & 5.5 & 5.5 & 2.5 & 0.8 \\
\hline $60-64$ & 1.09 & 0.91 & 9.5 & 4.8 & 3.1 & 0.8 \\
\hline $65-69$ & 2.15 & 1.59 & 12.3 & 6.3 & 3.8 & 1.6 \\
\hline $70-74$ & 4.14 & 2.29 & 17.9 & 8.7 & 5.0 & 0.5 \\
\hline $75-79$ & 8.51 & 4.49 & 29.3 & 13.6 & 5.7 & 1.0 \\
\hline $80-84$ & 17.71 & 7.46 & $34.4^{\mathrm{b}}$ & $16.1^{\mathrm{b}}$ & 6.7 & 1.4 \\
\hline $85-89$ & 32.31 & 14.84 & $39.6^{\mathrm{b}}$ & $18.7^{\mathrm{b}}$ & 7.7 & 1.8 \\
\hline $90-94$ & 41.43 & 24.96 & $44.7^{\mathrm{b}}$ & $21.2^{\mathrm{b}}$ & $7.7^{\mathrm{c}}$ & $1.8^{\mathrm{c}}$ \\
\hline $95+$ & 44.04 & 46.28 & $49.9^{\mathrm{b}}$ & $23.8^{\mathrm{b}}$ & $7.7^{\mathrm{c}}$ & $1.8^{\mathrm{c}}$ \\
\hline
\end{tabular}

${ }^{\text {a }}$ Radiographic fractures

${ }^{\mathrm{b}}$ Extrapolated from the available datapoints

${ }^{\mathrm{c}}$ Assumed to remain constant after age $85-89$ years

et al. in canton Geneva, Switzerland [27]. Those authors observed an unadjusted in-hospital mortality rate of $8 \%$ in women and $15 \%$ in men. The combination of their original data and the Swiss age distribution starting at age 50 years led to an age-adjusted excess mortality rate of 53 per 1,000 person-years in women and 206 per 1,000 person-years in men, in the first year after fracture. In the second to fifth years, excess mortality rates per year were 103 per 1,000 person-years in women and 127 per 1,000 person-years in men. Long-term excess mortality after vertebral fracture was modeled on relative risks of 1.6 in women and 1.2 in men, as found in the EPOS study after multivariate adjustment $[28,29,30]$. For both types of fracture, excess mortality was limited to a period of 5 years after fracture entry [10, 27, 29, 31, 32]. Excess mortality after distal forearm fracture and short-term excess mortality after vertebral fracture were not modeled [1]. To avoid an overestimation of total mortality, all-cause mortality was reduced by the approximate populationlevel impact of fracture-associated mortality.

The probability that a vertebral fracture would come to clinical attention and be treated was estimated to be $30 \%[33,34,35]$. The probability of an acute hospitalization episode was assumed to be $33 \%$ after a vertebral fracture had come to clinical attention $[1,35]$. In the case of distal forearm fracture, a hospitalization probability of $53.0 \%$ was estimated from the incidence data used and the inpatient cases with ICD-10 codes S52.5-6 reported to the SFSO in 2000. This estimate takes into account all patients that occupy a hospital bed, even be it for a few hours only.

Year 2000 acute care lengths of stay were calculated from the SFSO data. In the case of vertebral fracture, ICD-10 codes M48.5, M80.0-9, M84.0, M84.4 and T08 were taken into account. Participation in an inpatient rehabilitation program after hip fracture was assumed to occur in $68 \%$ of women and $36 \%$ of men, with a length of stay of 59 and 54 days, respectively [27]. Rehabilitation programs after vertebral or distal forearm fracture were not taken into account.
Swiss year 2000 census data were used to estimate gender- and age-specific probabilities of being cared for in a nursing home, and of being admitted to such an institution, for any reason. The overall share of fractureinduced nursing home admissions was assumed to be $8 \%$, following a German source [36]. Based on data from canton Geneva, Switzerland, the overall probability of long-term nursing home admission after hip fracture in those living in an apartment before the fracture event was assumed to be $18 \%$ [27, 37]. Genderand age-specific admission probabilities were estimated under the assumption of a linear increase with age. Residency in a nursing home for any reason and the event of being admitted to a nursing home due to hip fracture were modeled in parallel. Residency in a nursing home was counted as fracture-induced until a nursing home admission for any reason would have occurred. Nursing home admissions due to vertebral or distal forearm fractures were not taken into account.

Adopting a societal perspective, we assessed direct medical costs of acute inpatient hospital care, inpatient rehabilitation and nursing home residency by multiplying length of stay with the estimated daily real costs by type of institution as reported by the SFSO for the year 2000. The results were verified against Swiss and international data sources $[38,39,40,41]$. All costs are indicated in year 2000 Swiss francs (CHF). On 31 Dec 2000, CHF1 equaled 0.66 euros.

\section{Analysis of model output}

Using STATA/SE (version 8.0, Stata Corporation, College Station, Tex., USA) and standard statistical procedures, we analyzed the output data. Calculation of 95\% confidence intervals (95\% CIs) was based on biascorrected bootstrapping using 1,000 repetitions. Due to limitations of available computation time, calculation of CIs was restricted to key output parameters.

\section{Internal and external model validation}

Correct reproduction of main input parameters was examined to test the internal validity of the model. Comparisons included the gender and age distributions and life expectancies of the underlying demographic scenario, as well as gender- and age-specific incidence rates. External plausibility of results was assessed by comparison with published data as detailed in the Discussion.

\section{Sensitivity analysis}

While Monte Carlo simulation was used to deal with first-order uncertainty (individual variation in gender and age), the impact of second-order parameter uncertainty was assessed by classic deterministic sensitivity 
analysis. Ranges of variation are shown in Table 2. In order to limit calculation time, we combined several parameter changes that prompted fewer fracture events and lower costs, and tested them simultaneously in a best-case scenario. Parameter changes that prompted more fracture events and higher costs were tested in a worst-case scenario. Varied parameters comprised: gender- and age-specific incidences; osteoporosis attribution probabilities; treatment, hospitalization and rehabilitation probabilities; the probability of a new admission to a nursing home after hip fracture; lengths of stay; acute care, rehabilitation and nursing home costs per day. In a separate analysis, approximate outpatient hip fracture costs of CHF6,442 per case were added [42]. Background nursing home residency and disease-specific mortality were also varied separately. Additional analyses modeled disease-specific mortality as age-specific or replaced the SFSO main demographic scenario with alternative scenarios that described either a less or a more pronounced ageing of the population [19]. Finally, we repeated the main analysis but included a secular $1 \%$ per year rise of gender- and age-specific hip fracture incidence rates $[1,6]$.

\section{Results}

\section{Internal validation}

The gender and age distributions of the underlying demographic scenario were reproduced correctly. The proportion of women in the population aged 50 years or older was $54.6 \%(95 \%$ CI $54.4-54.7)$ in $2000,53.8 \%$ (95\% CI 53.7-53.9) in 2010 and $53.5 \%$ (95\% CI 53.3$53.6)$ in 2020. Mean age \pm SD of those aged 50 years or older rose from $65.0 \pm 11.0$ (95\% CI 64.9-65.0) years in 2000 and $65.2 \pm 10.9$ (95\% CI 65.2-65.2) years in 2010 to $65.6 \pm 10.8$ (95\% CI 65.6-65.6) years in 2020. Predicted life expectancy at age 50 years was $31.8 \pm 10.4(95 \%$ CI $31.7-32.0)$ years in 2000, 32.8 \pm 10.1 (95\% CI 32.6-32.9) years in 2010 and $33.4 \pm 9.6$ (95\% CI 33.3-33.6) years in 2020. These results compare well with the SFSO estimates of 32.0 years in 2000, 32.8 years in 2010 and 33.4 years in 2020. Gender- and age-specific fracture incidences used on the input side were also reproduced correctly. First hip fractures were estimated to occur at an age of 79.8 years, on average, in 2000 . This compares well with a broad estimate of 80.5 years as directly derived from the SFSO data. In the latter case, no distinction between first and repeated fractures could be made.

\section{Fractures}

Tables 3 and 4 summarize total and osteoporosisattributable fracture incidences and absolute fracture numbers by gender. For all parameters a rise is seen between 2000 and 2020, with the exception of the inci-

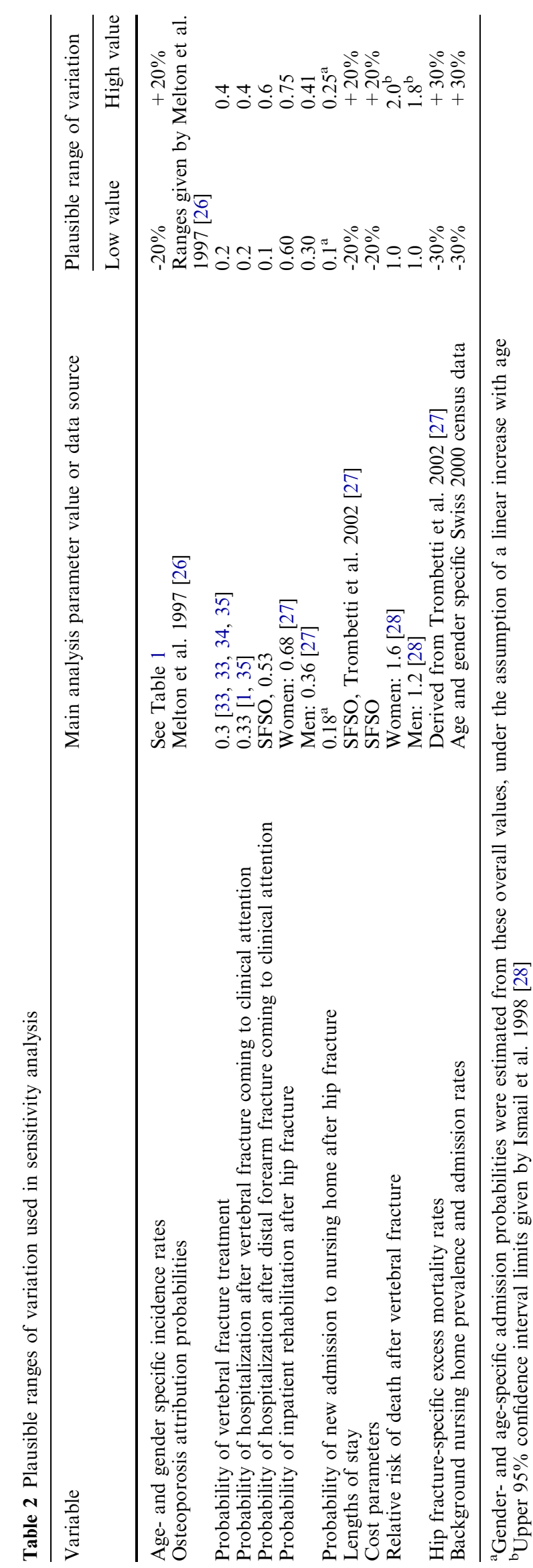



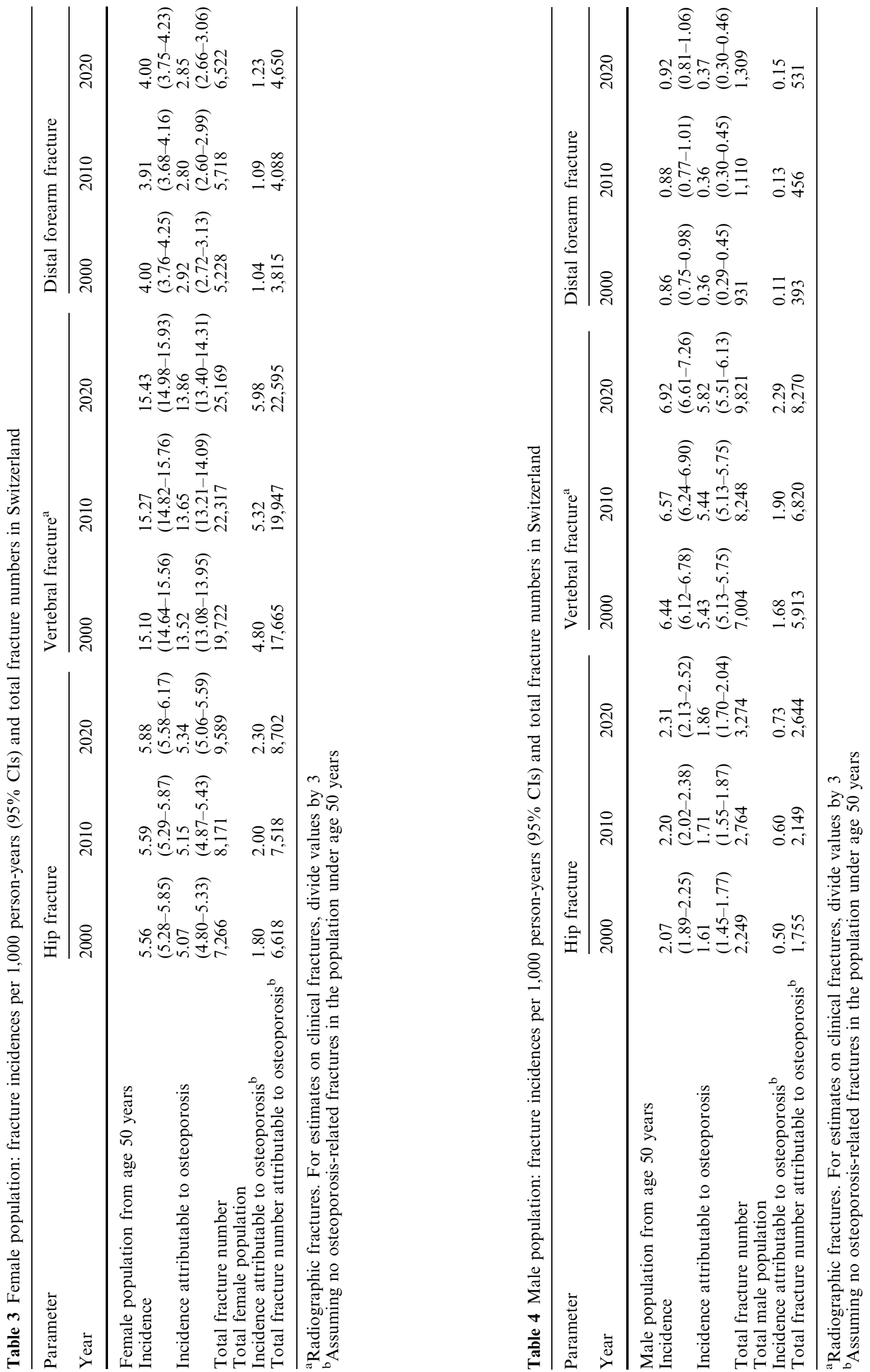
dence of distal forearm fractures in women aged 50 years and over, which is constant at the all-fracture level and slightly decreases when only osteoporosis-attributable fractures are taken into account. Related absolute minima will occur in 2010.

For all ages combined, osteoporosis-attributable hip fracture incidence will rise from 1.16 to 1.54 per 1,000 person-years $(+32.8 \%)$, osteoporosis-attributable vertebral fracture incidence from 3.28 to 4.18 per 1,000 person-years $(+27.4 \%)$, and osteoporosis-attributable distal forearm fracture incidence from 0.59 to 0.70 per 1,000 person-years $(+18.6 \%)$. Osteoporosis-attributable fracture numbers at the total population level will rise from 8,375 to $11,353(+35.6 \%)$ in the case of hip fracture, from 23,584 to $30,883(+30.9 \%)$ in the case of vertebral fracture, and from 4,209 to $5,186(+23.2 \%)$ in the case of distal forearm fracture.

\section{Lifetime fracture risk}

For all combinations of fracture type and gender, lifetime risk at age 50 years will rise between 2000 and 2020 . Lifetime hip fracture risk will rise from $14.7 \%$ to $16.4 \%$ (women: $20.9 \%$ to $23.1 \%$, men: $8.7 \%$ to $9.7 \%$ ). Lifetime vertebral fracture risk will rise from $30.7 \%$ to $33.8 \%$ (women: $42.6 \%$ to $46.1 \%$, men: $19.1 \%$ to $21.7 \%$ ), and distal forearm fracture risk from $8.1 \%$ to $8.9 \%$ (women: $13.8 \%$ to $14.9 \%$, men: $2.7 \%$ to $3.1 \%$ ). Osteoporosisattributable lifetime risk will rise from $13.0 \%$ to $14.4 \%$ (women: $19.2 \%$ to $21.2 \%$, men: $7.0 \%$ to $7.6 \%$ ) in the case of hip fracture, from $27.8 \%$ to $30.7 \%$ (women: $39.0 \%$ to $42.5 \%$, men: $17.0 \%$ to $19.0 \%$ ) in the case of vertebral fracture, and from $5.6 \%$ to $6.1 \%$ (women: $10.1 \%$ to $10.9 \%$, men: $1.2 \%$ to $1.5 \%$ ) in the case of distal forearm fracture.

\section{Resource use}

Table 5 shows the number of acute hospitalizations and the days spent in acute care hospitals, inpatient rehabilitation facilities, and nursing homes, due to fractures, in 1000 persons aged 50 years and over, in 2000, 2010 and 2020. Results for the Swiss population from age 50 on are added. Days of stay occurring until 1 year after fracture entry are taken into account. For all parameters, a rise is seen between 2000 and 2020. However, estimates per 1,000 persons show a non-monotonic development in some cases, with their maxima or minima in 2010. Population-level increases are more pronounced due to the growth of population size.

\section{Costs}

Figure 2 shows direct medical inpatient costs arising in the Swiss population from age 50 on, induced by fractures in 2000, 2010 and 2020, during the first year after

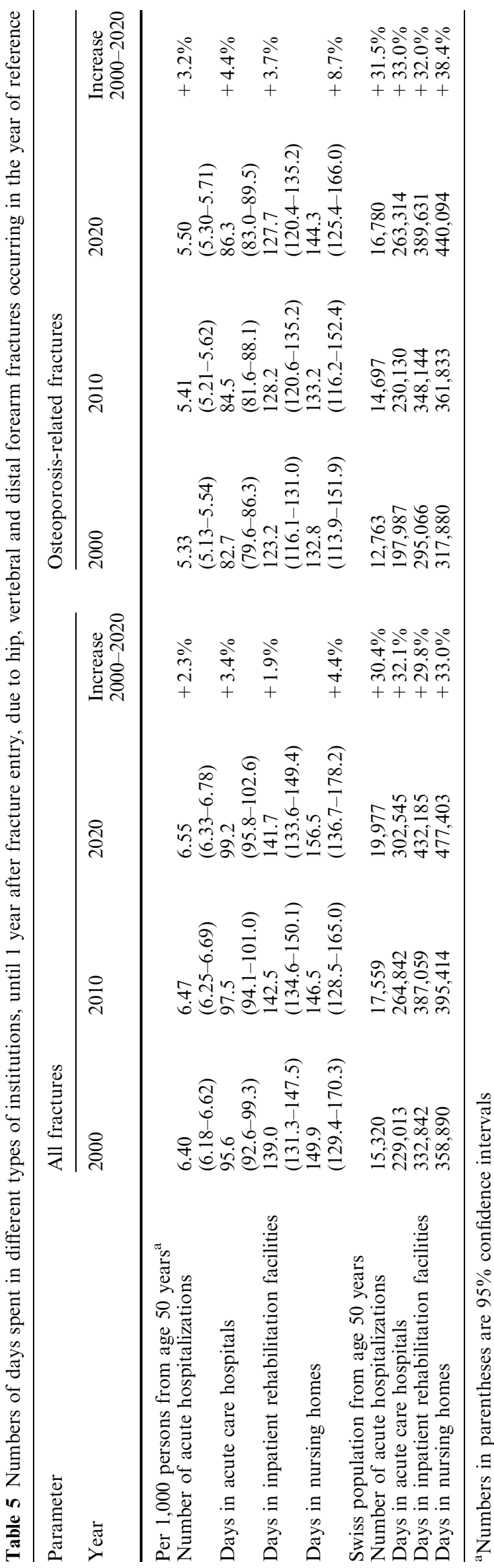




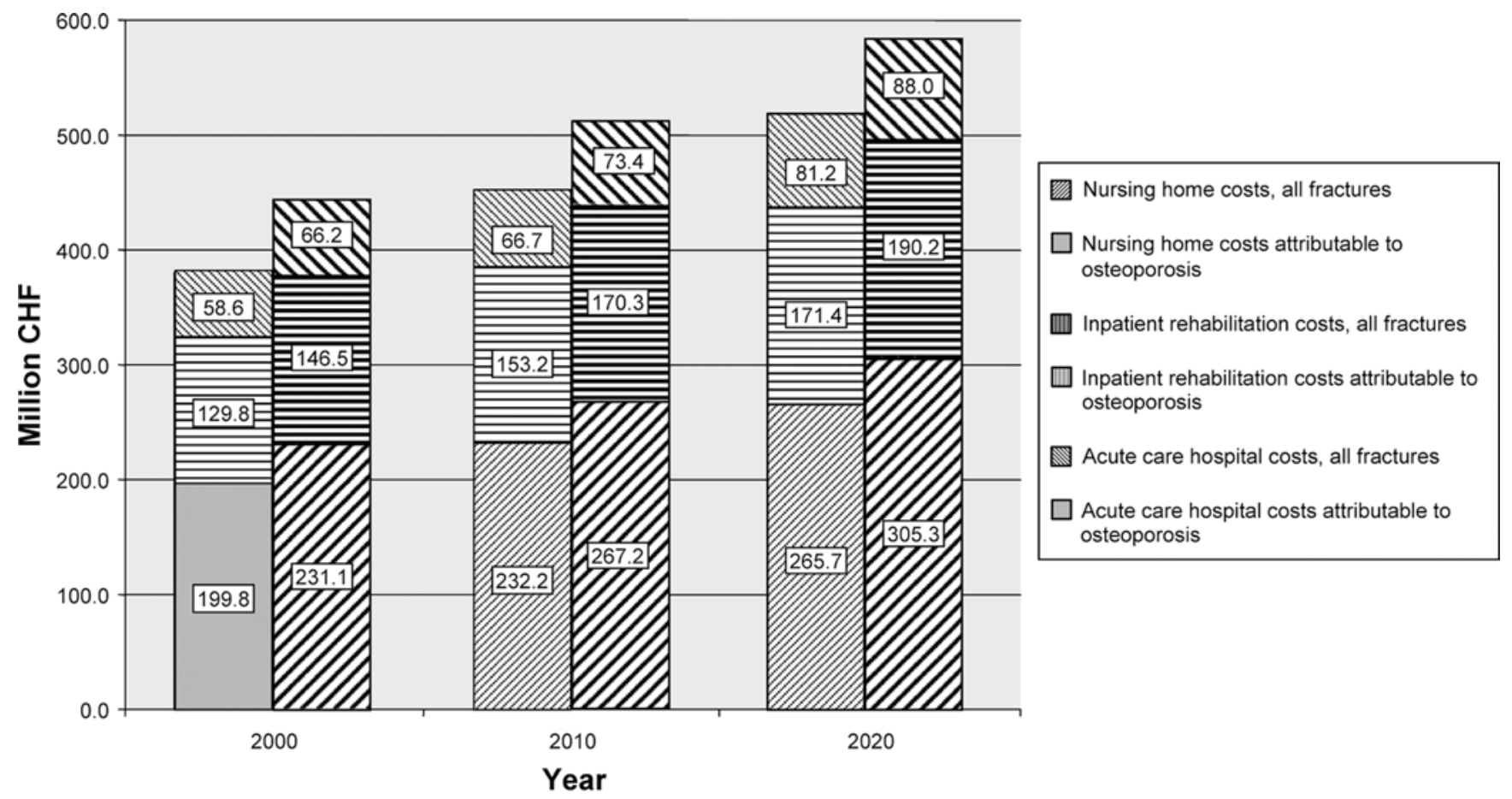

Fig. 2 Inpatient costs of fractures of the hip, vertebrae and forearm, until 1 year after fracture entry, occurring in the Swiss population from age 50 years

fracture. Costs of all fractures and of those attributable to osteoporosis are presented in parallel.

Total first-year inpatient costs will rise by $31.5 \%$ at the all-fracture level, from CHF443.7 million (CI 422.8462.9 million) to CHF583.5 million (CI 559.2609.7 million). Point estimates correspond to $1.0 \%$ and $1.3 \%$ of Swiss health care expenditure in 2000 . At the osteoporosis-attributable fracture level there will be a rise by $33.5 \%$, from CHF388.2 million (CI 369.1406.4 million) to CHF518.3 million (CI 494.9544.7 million). Point estimates correspond to $0.9 \%$ and $1.2 \%$ of Swiss health care expenditure in 2000.

The relative shares of acute care hospital, inpatient rehabilitation and nursing home costs in the first year after osteoporosis-related fracture will remain fairly constant over time. In 2000, acute hospital care contributes $51.5 \%$ (2020: $51.3 \%$ ), inpatient rehabilitation contributes 33.4\% (2020: $33.1 \%$ ), and nursing home care $15.1 \%(2020: 15.7 \%)$. Results at the all-fracture level are similar.

The relative importance of nursing home costs is much higher if undiscounted lifetime inpatient costs from age 50 years on are considered. Long-term cost consequences of fractures are included in this perspective, which results in a proportion of nursing home costs that is near constant over time at $53.3 \%-54.3 \%$.

These percentages broadly reflect the contribution of nursing home costs to yearly fracture- and osteoporotic fracture-induced inpatient costs taking into account the consequences of earlier fractures. If an average value of $53.8 \%$ is adopted, yearly fracture-related inpatient costs can be estimated at CHF817.2 million in 2000 and at CHF1,072.4 million in $2020(+31.2 \%)$, which correspond to $1.9 \%$ and $2.5 \%$ of Swiss health care expenditure in 2000. Osteoporosis-attributable costs can be estimated at CHF713.4 million in 2000 and at CHF946.2 million in $2020(+32.6 \%)$, which correspond to $1.6 \%$ and $2.2 \%$ of Swiss health care expenditure in 2000 .

Lifetime fracture-related inpatient costs from age 50 on, per 1,000 persons observed, will rise from CHF13.7 million in 2000 (CI 12.3-15.4 million; discounted by $3 \%$ : CHF5.4 million) to CHF 15.2 million in 2020 (CI 13.8-16.6 million; discounted: CHF5.7 million). If only osteoporosis-attributable fractures are regarded, the rise will be from CHF11.9 million in 2000 (CI 10.6-13.3 million; discounted: CHF4.6 million) to CHF13.5 million in 2020 (CI 12.3-15.0 million; discounted: CHF5.0 million).

\section{Sensitivity analysis}

The effects of input parameter variation on key outcome parameters are shown in Table 6.

Implementation of the best and worst case scenarios described in the Methods strongly impacted on all epidemiologic and economic outcome parameters. For example, the incidence of year 2000 osteoporosisattributable hip fractures, for all ages combined, was changed by $\pm 31.9 \%$. Population level, osteoporosisattributable, first-year inpatient costs were reduced by $57.7 \%$ in the best case and increased by $93.7 \%$ in the worst case. If estimated outpatient hip fracture costs of CHF6,552 per case were taken into account, this led to an absolute increase of osteoporosis-attributable costs 


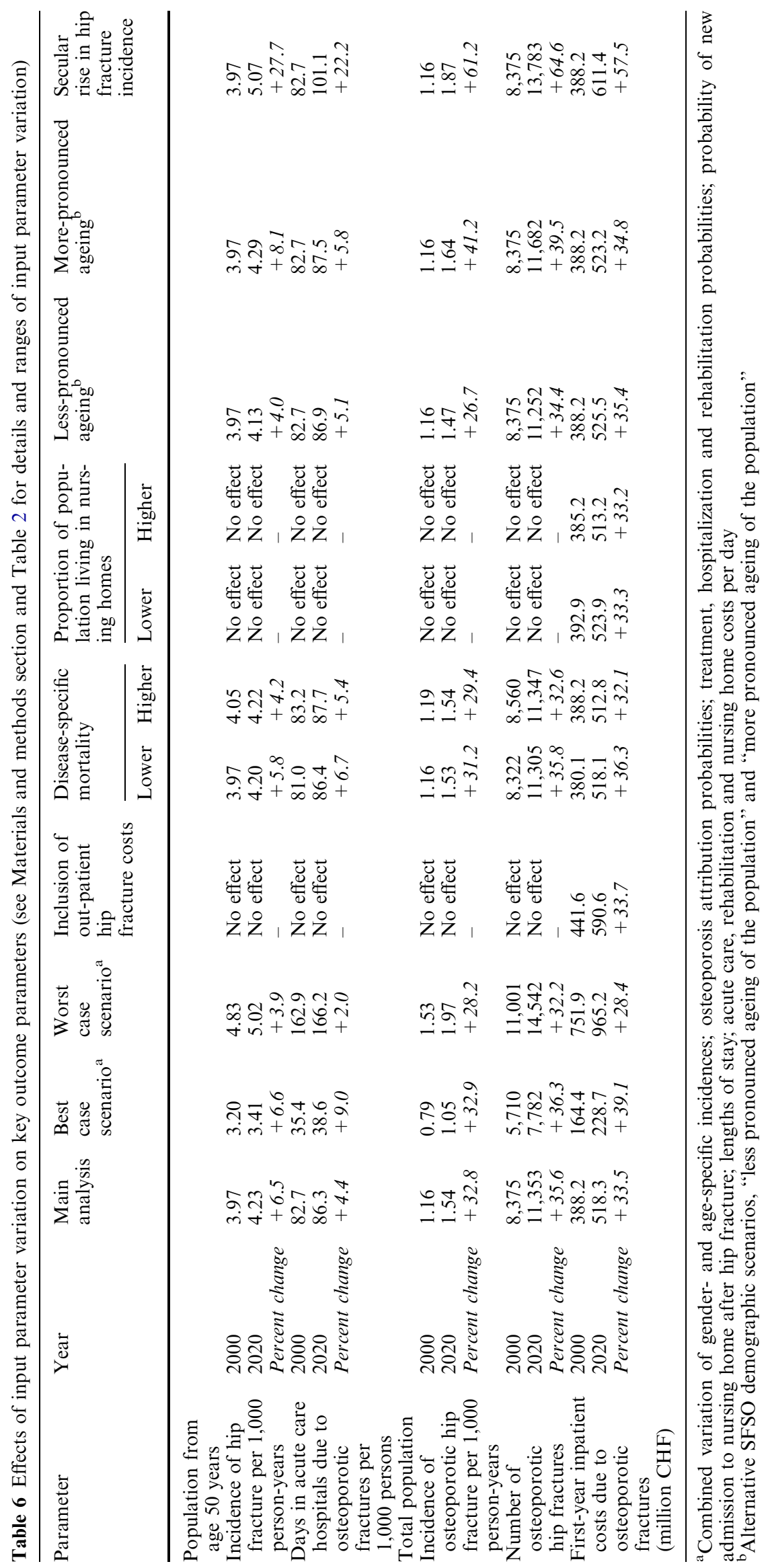


by $13.8 \%$. In contrast, if we varied the proportion of the population that were living in a nursing home, varied the level of disease-specific mortality, or modeled diseasespecific mortality as age-specific, it hardly affected the absolute results. Relative parameter changes between 2000 and 2020 were only marginally affected by all modifications named so far. When the SFSO main demographic scenario was replaced by alternative scenarios that described a less-pronounced or a more-pronounced ageing of the population, relative increases in the incidence of osteoporosis-attributable fractures between 2000 and 2020 were slightly less pronounced in the former case and more pronounced in the latter (in the case of hip fracture, $+26.7 \%$ and $+41.2 \%$ compared to $+32.8 \%$ in the main analysis). However, there was no impact on the resource use and cost results. When a $1 \%$ per year secular rise in the incidences of gender- and agespecific hip fractures was modeled, relative changes between 2000 and 2020 were inflated by a factor of 2 to 4 when compared with the main analysis. The incidence of osteoporosis-attributable hip fractures increased by $+61.2 \%$, and population level, osteoporosis-attributable, first-year inpatient costs by $+57.5 \%$.

\section{Discussion}

The modeling framework described here allows one to assess the epidemiologic and economic consequences of osteoporotic hip, vertebral and distal forearm fractures. There is a particular focus on change over time, e.g., related to demographic developments. If suitable input data are available, the model can be applied to a wide variety of countries and settings. While the application to Switzerland, presented here as a test case, was purely descriptive, the epidemiological and economic impact of new preventive or treatment strategies, or of any changes occurring in medical practice, can easily be modeled as soon as related effect estimates are available.

To our knowledge this is the second study, internationally, that used a Markov process model, and the first one that used the Monte Carlo technique, to simulate the development of osteoporotic fracture incidences and numbers, associated resource use, and cost over an extended period of time [12]. While future fracture occurrence alone could be estimated by simpler means, the synthesis of data from various sources and the assessment of several interlinked output parameters are most consistently achieved by the use off the Markov approach. More importantly, long-term observation of simulated individual disease histories, e.g., allowing for the estimation of lifetime fracture risk, requires such a methodology $[12,17]$. The advantages of Monte Carlo simulation in particular are highlighted by a comparison with the methodological approach described in a recently published work by Burge et al., who assessed the epidemiology and economic impact of osteoporosis in Florida for 2000-2025 [12]. Relying on a conventional Markov cohort model, Burge et al. had to run a large number of separate simulations, one for each combination of year of age and race. Simulation outputs were combined, and the impact of demographic change was assessed by way of separate procedures outside the Markov module. By contrast, the Monte Carlo technique enabled us to forego additional modeling steps. Additional calculations were limited to the statistics required to address the chance component inherent in all Monte Carlo-based results.

While models are generally characterized by a reduction in complexity compared to reality, some simplifications in the present case were dictated by an anticipated lack of appropriate input data. For example, we relied on a set of Markov states that solely described fracture event history, in contrast to some osteoporosis models that incorporated functional status or type of residence at the disease state level $[8,10,16]$. Owing to a lack of detailed fracture incidence data that distinguished between persons without and with osteoporosis, modeling of fracture entries was not based on the absence or presence of the underlying disease [10]. Different fracture incidences in persons without or with previous fractures, or in persons living either in the community or in nursing homes, were not taken into account [10]. The model was built in such a way that the simplifications described can be abandoned easily when adequate input data become available. Technical correctness of the model was assessed by comparison of output parameters with related input parameters, with completely satisfactory results.

Besides developing and testing methodology, this study aimed at closing a gap of information on the future occurrence and consequences of osteoporosisattributable hip, vertebral, and distal forearm fractures in Switzerland. According to our results, the incidence of these fracture types at the Swiss population level will rise by $19 \%-33 \%$ between 2000 and 2020 . Corresponding absolute fracture numbers will rise by $23 \%-36 \%$. Related direct medical inpatient costs per year are predicted to increase by $33 \%$.

The expected increase in the number of osteoporosisrelated hip fractures, from 8,375 in 2000 to 11,353 in 2020 , confirms the magnitude of earlier estimates $[1,6$, 7]. For Switzerland in 2020, Meine et al. [15] expected 15,000 hip fractures and Lippuner and Jaeger [14] expected 14,436, for all ages combined and without excluding non-osteoporotic fractures. Calculated lifetime risks are well in the range to be expected from the literature. For example, our result of a $21 \%$ lifetime hip fracture risk in women aged 50 years in 2000 compares well with published estimates from various industrialized countries, indicating a risk of $14 \%-23 \%$ at this age $[4,8$, $10,20,23]$. In men aged 50 years, our result of $9 \%$ compares with published estimates of from $6 \%-11 \%$ $[23,35,43]$.

Constant or slightly decreasing incidence rates of distal forearm fractures, as observed in women aged 50 years and over, and non-monotonic developments over time in some resource use parameters, are explained by 
shifts in the age structure above age 50 as modeled by the SFSO main scenario. Residual influences of chance may have played an additional role.

For the fracture types taken into account here, Lippuner et al. reported 290,972 osteoporosisattributable days spent in acute care hospitals in 1992 and related costs of CHF245.9 million [13]. Our corresponding results of 197,987 hospital days and costs of CHF199.8 million in 2000 are distinctly lower. While the different registration methods and coding systems used might have contributed to this effect, the main reason lies in reduced lengths of stay. In particular, mean acute care length of stay after hip fracture fell dramatically, from 29.1 days in 1992 to 17.7 days in 2000 [13]. It can be assumed that this decrease was enabled by improved medical practice but also encouraged by budgetary constraints in the Swiss health care system. It may have been accompanied by a still unmeasured increase in the use of outpatient medical and nursing services and, consequently, in outpatient costs. Missing information on outpatient costs hindered a realistic assessment of total direct medical costs.

The finding that long-term nursing home costs contributed $54 \%$ of total inpatient costs is consistent with findings from 1998 onwards, which indicated that longterm care costs are responsible for $40 \%-75 \%$ of osteoporosis-related inpatient costs in the USA [12].

Sensitivity analyses demonstrated stable relative parameter changes between 2000 and 2020 except for when a $1 \%$ per year secular rise of fracture incidence was modeled. In fact, there is no strong evidence for an ongoing secular rise in Europe or in the USA [1, 6]. Absolute results, however, showed considerable variation, which highlighted that relevant uncertainty was present in some of the input parameters available. These were of different quality and, in part, of non-Swiss origin. For example, for vertebral and distal forearm fractures, European incidence data had to be used and, in the latter case, adjusted for geographic differences. This was justified by various literature sources, but, still, the inputs derived may, to a certain extent, deviate from Swiss reality [22, 25, 35, 44].

The osteoporosis attribution probabilities applied, reported by Melton et al., were estimated by an expert panel that used a Delphi process, and they compare well with earlier estimates published by Phillips et al. [26, 45]. Attribution probabilities have been used by several authors to model osteoporosis-related fracture occurrence $[12,13]$.

Modeling of hip fracture mortality was based on Swiss short-term and long-term data reported by Trombetti et al. [27], which are in line with various Swiss and international data sources $[31,37,46]$. In particular, 1 -year cumulative mortality was near identical in the study by Trombetti et al. (women: 19\%, men: 39\%), in an earlier Swiss study by Schürch et al. (women: $21 \%$, men: $35 \%$ ) [37], and in the Australian study by Center et al. (women: 20\%; men: 37\%) [31].
The estimate of a $53 \%$ hospitalization probability after distal forearm fracture in the population aged 50 years or older reflects Swiss hospitalization data and, thus, ensures consistency in our economic results. $\mathrm{Pa}$ tients that occupy a hospital bed for only a few hours were taken into account here, which may explain, in part, why this value is in accordance with a Swiss source that indicated a hospitalization probability of $70 \%$ at age 85 years, but not with two international sources that hinted at a probability of approximately $10 \%$ only from age 40 onwards [9, 35, 47]. The latter value was used as a lower boundary in sensitivity analysis.

This study focused on the occurrence and impact of osteoporosis-attributable hip, vertebral, and distal forearm fractures. An assessment of total osteoporosisrelated fracture occurrence, resource use and cost would have to take into account additional fracture sites, such as the humerus, ribs and pelvis, but it was not undertaken for reasons of data availability. Another slight tendency for the model to underestimate the impact of osteoporosis may have been introduced by our not considering osteoporotic fracture occurrence under the age of 50 years. Due to a lack of data, inpatient rehabilitation episodes caused by vertebral and distal forearm fractures could not be taken into account, which may have impacted on costs estimates.

In summary, in Switzerland the incidences of osteoporotic hip, vertebral and distal forearm fractures will rise, respectively, by $33 \%, 27 \%$, and $19 \%$, between 2000 and 2020, if current prevention and treatment patterns are maintained. Corresponding absolute fracture numbers per year will rise by $36 \%, 31 \%$, and $23 \%$. The increase in hip fractures will be most pronounced. Main causes are (1) a shift toward higher ages within the population from age 50 years on, (2) a relative growth of the population from age 50 on within the total population, and (3) absolute population growth. Main assumptions are that demographic reality will essentially confirm the SFSO main scenario and that age- and gender specific incidence rates will remain constant. Related direct medical inpatient costs per year are predicted to increase by $33 \%$ (CHF232.8 million), but this result is affected by uncertainty due to a lack of knowledge of future developments of treatment patterns, economic circumstances, and resource unit prices. Moreover, currently, total direct medical costs cannot be estimated due to missing data on outpatient costs. When additional information becomes available, this modeling framework can be used for a re-assessment.

In more general terms, this modeling framework, which focuses on hip, vertebral, and distal forearm fractures, can be applied to a wide variety of situations in order to forecast future developments and assess the impact of changing medical practice and changing economic circumstances. The incorporation of additional fracture sites is also feasible. Limitations will usually be due to the limited availability of adequate input data. 
Acknowledgments This study was supported by an unrestricted, educational grant from Merck Sharp \& Dohme-Chibret AG, Glattbrugg, Switzerland.

\section{References}

1. Cummings SR, Melton LJ (2002) Epidemiology and outcomes of osteoporotic fractures. Lancet 359:1761-1767

2. Seeley DG, Browner WS, Nevitt MC, Genant HK, Scott JC, Cummings SR (1991) Which fractures are associated with low appendicular bone mass in elderly women? The Study of Osteoporotic Fractures Research Group. Ann Intern Med 115:837-842

3. Dennison E, Cooper C (2000) Epidemiology of osteoporotic fractures. Horm Res 54 [Suppl 1]:58-63

4. Cooper C (1997) The crippling consequences of fractures and their impact on quality of life. Am J Med 103:12S-17S

5. Cooper C, Campion G, Melton LJ 3rd (1992) Hip fractures in the elderly: a world-wide projection. Osteoporos Int 2:285-289

6. Gullberg B, Johnell O, Kanis JA (1997) World-wide projections for hip fracture. Osteoporos Int 7:407-413

7. Sanders KM, Nicholson GC, Ugoni AM, Pasco JA, Seeman E, Kotowicz MA (1999) Health burden of hip and other fractures in Australia beyond 2000. Projections based on the Geelong Osteoporosis Study. Med J Aust 170:467-470

8. Chrischilles EA, Butler CD, Davis CS, Wallace RB (1991) A model of lifetime osteoporosis impact. Arch Intern Med 151:2026-2032

9. Chrischilles E, Shireman T, Wallace R (1994) Costs and health effects of osteoporotic fractures. Bone 15:377-386

10. Doherty DA, Sanders KM, Kotowicz MA, Prince RL (2001) Lifetime and five-year age-specific risks of first and subsequent osteoporotic fractures in postmenopausal women. Osteoporos Int 12:16-23

11. Braithwaite RS, Col NF, Wong JB (2003) Estimating hip fracture morbidity, mortality and costs. J Am Geriatr Soc 51:364-370

12. Burge RT, King AB, Balda E, Worley D (2003) Methodology for estimating current and future burden of osteoporosis in state populations: application to Florida in 2000 through 2025. Value Health 6:574-583

13. Lippuner K, von Overbeck J, Perrelet R, Bosshard H, Jaeger P (1997) Incidence and direct medical costs of hospitalizations due to osteoporotic fractures in Switzerland. Osteoporos Int 7:414-425

14. Lippuner K, Jaeger P (1998) Direkte Spitalkosten durch osteoporosebedingte Hüftfrakturen in der Schweiz heute und im Jahr 2020: Ein sozioökonomischer Alptraum. Schweiz Ärztezeitung 79:690-697

15. Meine J, Regazzoni P, Konig W (1993) Fractures of the proximal femur: rehabilitation and socioeconomic repercussions. Z Unfallchir Versicherungsmed 86:66-80

16. Sendi P, Palmer AJ (2000) Modeling the socioeconomic impact of osteoporosis-related hip fractures in Switzerland. Osteoporos Int 11:92-94

17. Briggs A, Sculpher M (1998) An introduction to Markov modelling for economic evaluation. Pharmacoeconomics 13:397-409

18. Miller DK, Homan SM (1994) Determining transition probabilities: confusion and suggestions. Med Decis Making 14:52-58

19. Bundesamt für Statistik (2002) Szenarien zur Bevölkerungsentwicklung der Schweiz 2000-2060. Vollständiger Szenariensatz. Neuchâtel: Bundesamt für Statistik

20. Kanis JA, Johnell O, De Laet C, Jonsson B, Oden A, Ogelsby AK (2002) International variations in hip fracture probabilities: implications for risk assessment. J Bone Miner Res 17:1237-1244

21. The European Prospective Osteoporosis Study (EPOS) Group (2002) Incidence of vertebral fracture in Europe: results from the European Prospective Osteoporosis Study (EPOS). J Bone Miner Res 17:716-724
22. de Laet CE, Pols HA (2000) Fractures in the elderly: epidemiology and demography. Baillieres Best Pract Res Clin Endocrinol Metab 14:171-179

23. Kanis JA, Johnell O, Oden A, Sembo I, Redlund-Johnell I, Dawson A, et al (2000) Long-term risk of osteoporotic fracture in Malmö. Osteoporos Int 11:669-674

24. Black DM, Cooper C (2000) Epidemiology of fractures and assessment of fracture risk. Clin Lab Med 20:439-453

25. Ismail AA, Pye SR, Cockerill WC, Lunt M, Silman AJ, Reeve J, et al (2002) Incidence of limb fracture across Europe: results from the European Prospective Osteoporosis Study (EPOS). Osteoporos Int 13:565-571

26. Melton LJ 3rd, Thamer M, Ray NF, Chan JK, Chesnut $\mathrm{CH}$ 3rd, Einhorn TA, et al (1997) Fractures attributable to osteoporosis: report from the National Osteoporosis Foundation. J Bone Miner Res 12:16-23

27. Trombetti A, Herrmann F, Hoffmeyer P, Schurch MA, Bonjour JP, Rizzoli R (2002) Survival and potential years of life lost after hip fracture in men and age-matched women. Osteoporos Int 13:731-737

28. Ismail AA, O'Neill TW, Cooper C, Finn JD, Bhalla AK, Cannata JB, et al (1998) Mortality associated with vertebral deformity in men and women: results from the European Prospective Osteoporosis Study (EPOS). Osteoporos Int 8:291297

29. Cooper C, Atkinson EJ, Jacobsen SJ, O'Fallon WM, Melton LJ 3rd (1993) Population-based study of survival after osteoporotic fractures. Am J Epidemiol 137:1001-1005

30. Ensrud KE, Thompson DE, Cauley JA, Nevitt MC, Kado DM, Hochberg MC, et al (2000) Prevalent vertebral deformities predict mortality and hospitalization in older women with low bone mass. Fracture Intervention Trial Research Group. J Am Geriatr Soc 48:241-249

31. Center JR, Nguyen TV, Schneider D, Sambrook PN, Eisman JA (1999) Mortality after all major types of osteoporotic fracture in men and women: an observational study. Lancet 353:878-882

32. Melton LJ 3rd (2000) Excess mortality following vertebral fracture. J Am Geriatr Soc 48:338-339

33. Cooper C, Atkinson EJ, Kotowicz M, O'Fallon WM, Melton LJ 3rd (1992) Secular trends in the incidence of postmenopausal vertebral fractures. Calcif Tissue Int 51:100-104

34. Melton LJ 3rd, Lane AW, Cooper C, Eastell R, O'Fallon WM, Riggs BL (1993) Prevalence and incidence of vertebral deformities. Osteoporos Int 3:113-119

35. Bonjour JP, Burckhardt P, Dambacher M, Kraenzlin ME, Wimpfheimer C (1997) [Epidemiology of osteoporosis]. Schweiz Med Wochenschr 127:659-667

36. Pientka L (1996) Die ökonomische Bedeutung der Osteoporose in Deutschland. Deutsches Ärztemagazin 8:44-52

37. Schürch MA, Rizzoli R, Mermillod B, Vasey H, Michel JP, Bonjour JP (1996) A prospective study on socioeconomic aspects of fracture of the proximal femur. J Bone Miner Res 11:1935-1942

38. Dolan P, Torgerson DJ (1998) The cost of treating osteoporotic fractures in the United Kingdom female population. Osteoporos Int 8:611-617

39. Haentjens P, Autier P, Barette M, Boonen S (2001) The economic cost of hip fractures among elderly women. A one-year, prospective, observational cohort study with matched-pair analysis. Belgian Hip Fracture Study Group. J Bone Joint Surg Am 83-A:493-500

40. Gabriel SE, Tosteson AN, Leibson CL, Crowson CS, Pond GR, Hammond CS, et al (2002) Direct medical costs attributable to osteoporotic fractures. Osteoporos Int 13:323-330

41. Wiktorowicz ME, Goeree R, Papaioannou A, Adachi JD, Papadimitropoulos E (2001) Economic implications of hip fracture: health service use, institutional care and cost in Canada. Osteoporos Int 12:271-278

42. Szucs TD, Häuselmann HJ (2000) Die Wirtschaftlichkeit von Alendronat in der Behandlung der postmenopausalen Osteoporose. Gesundh Ökon Qual Manag 5:99-106 
43. Johnell O, Gullberg B, Allander E, Kanis JA (1992) The apparent incidence of hip fracture in Europe: a study of national register sources. MEDOS Study Group. Osteoporos Int 2:298-302

44. Wasnich RD (1997) Epidemiology of osteoporosis in the United States of America. Osteoporos Int 7 [Suppl 3]:S68-72

45. Phillips S, Ray NF, Jacobs J, Wright WE (1988) The direct medical costs of osteoporosis for American women aged 45 and older, 1986. Bone 9:271-279
46. Diamond TH, Thornley SW, Sekel R, Smerdely P (1997) Hip fracture in elderly men: prognostic factors and outcomes. Med J Aust 167:412-415

47. Oskam J, Kingma J, Klasen HJ (1998) Fracture of the distal forearm: epidemiological developments in the period 19711995. Injury 29:353-355 